\title{
PRODUÇÃO DE PORTA-ENXERTOS EM TUBETES E ENXERTIA PRECOCE DA PINHEIRA (Annona squamosa L.) ${ }^{1}$
}

\author{
EURICO EDUARDO PINTO DE LEMOS ${ }^{2}$, TACIANA DE LIMA SALVADOR ${ }^{3}$, \\ MARIA QUITERIA CARDOSO DOS SANTOS ${ }^{3}$, LEILA DE PAULA REZENDE ${ }^{4}$, \\ TATIANA DE LIMA SALVADOR ${ }^{5}$, HULLY MONAÍSY ALENCAR LIMA ${ }^{3}$
}

RESUMO-O objetivo deste trabalho foi estabelecer um protocolo para a enxertia precoce de pinheira em porta-enxertos produzidos em tubetes como substituto do tradicional sistema de enxertia que utiliza portaenxertos de 12 meses produzidos em sacolas plásticas. $\mathrm{O}$ trabalho foi conduzido com três métodos de enxertia (borbulhia em escudo, garfagem de topo em fenda cheia e garfagem lateral em fenda cheia) e quatro idades dos porta-enxertos ( $3 ; 5 ; 7$ e 9 meses). Os porta-enxertos foram avaliados durante nove meses com relação às variáveis: comprimento da planta, diâmetro do caule, número de folhas e área foliar. Cada procedimento de enxertia foi avaliado por 30 dias através da percentagem de pegamento. Os porta-enxertos produzidos nos tubetes maiores apresentaram-se mais desenvolvidos para todas as variáveis, todavia a percentagem de pegamento dos enxertos foi mais influenciada pelo método de enxertia do que pelo tamanho de tubete. A garfagem de topo em fenda cheia mostrou-se como o melhor método para a enxertia precoce, pois já aos três meses de idade dos porta-enxertos apresentou taxa de pegamento de $96,69 \%$. O método de garfagem lateral em fenda cheia apresentou taxas semelhantes a partir dos cinco meses de idade dos porta-enxertos. $\mathrm{O}$ método de borbulhia apresentou baixo pegamento inicial $(<50 \%)$, mas a cada nova data de enxertia o pegamento foi aumentando e atingiu valores superiores a $80 \%$ aos sete meses de idade.

Termos para indexação: ata, pinha, fruta-do-conde, propagação.

\section{PRODUCTION OF ROOTSTOCKS IN TUBETTES AND EARLY GRAFTING OF SUGAR-APPLE (Annona squamosa L.)}

\begin{abstract}
The objective of this work was to establish a protocol for early grafting in sugar apple seedlings developed in small capacity plastic tubettes as a substitute for the traditional grafting system that uses 12 months-old seedlings developed in plastic bags. The work was carried out with three budding/grafting methods (chip budding, split graft and side-stub graft) and four rootstocks ages (3, 5, 7 and 9 months). The rootstocks were evaluated for 9 months with regard to the following variables: length of the plant, diameter of stem, leaf number and leaf area. Each budding/grafting procedure was evaluated after 30 days and the percentage of union. The rootstocks produced in bigger tubetes showed to be more developed for all variables during the evaluated period. The success of the union did not vary between the two types of containers. The split graft revealed to be the best method as it presented a $96,69 \%$ union success in the early 3 month-old rootstocks. The method side-stub graft presented similar percentage rates from 5 months-old rootstocks. The chip budding method initially presented a low success union rate $(<50 \%)$, but it increased at each new budding date and reached $80 \%$ union success in 7 months-old rootstocks.
\end{abstract}

Index terms: sweetsop, custard apple, saramuya, propagation.

\footnotetext{
1(Trabalho 163-09). Recebido em: 30-06-2009. Aceito para publicação em: 13-04-2010.

${ }^{2} \mathrm{Eng}^{\circ}$. Agr ${ }^{\circ}$.Professor Associado, PhD, Laboratório de Biotecnologia Vegetal, Centro de Ciências Agrárias, Universidade Federal de Alagoas, BR 104 Norte, Km 85, Rio Largo-AL, 57100-000, e-mail: eepl@uol.com.br

${ }^{3}$ Enga $^{\mathrm{a}}$. Agr ${ }^{\mathrm{a}}$. Mestranda em Agronomia - Centro de Ciências Agrárias, Universidade Federal de Alagoas - UFAL, Bolsista CNPq. E-mail: tacianalima11@hotmail.com; quiteriacardoso@hotmail.com; hully_monaisy@hotmail.com

${ }^{4} E_{n g}{ }^{a}$. Agr ${ }^{a}$. Dra . Professora Adjunta, Centro de Ciências Agrárias, Universidade Federal de Alagoas - UFAL. E-mail: leilarezende02@hotmail.com

${ }^{5}$ Aluna do Curso de Agronomia, Universidade Federal de Alagoas - UFAL. Bolsista Pibic. E-mail: tatinhalima.11@hotmail.com
} 


\section{INTRODUÇÃO}

A pinheira (Annona squamosa L.) é uma pequena árvore frutífera com folhas decíduas e muitos ramos laterais. Sua origem e domesticação são atribuídas ao norte da América do Sul e América Central/Caribe (OCHSE et al., 1974). Acredita-se que foi primeiramente introduzida na Bahia, em 1626, pelo Conde de Miranda, o que explica seu nome em algumas regiões do Brasil - "fruta-do-conde" (LEON, 1987, PINTO et al., 2005).

Pertencente à família das anonáceas, é uma fruteira tropical cultivada no Estado de Alagoas há mais de um século. Sua produção está concentrada principalmente nos municípios de Palmeira dos Índios, Estrela de Alagoas e Igaci, sendo a principal cultura de valor econômico para centenas de pequenos agricultores (OLIVEIRA et al., 2005).

A produção de porta-enxertos é uma das etapas fundamentais na formação de mudas de fruteiras de qualidade. Porta-enxertos vigorosos e bem formados podem melhorar e influenciar positivamente a taxa de pegamento dos enxertos. Aliás, é da perfeita compatibilidade e da sintonia fisiológica que depende em grande parte o sucesso da relação porta-enxerto/ enxerto (KITAMURA et al., 2004).

Os elevados custos de produção de mudas têm levado viveiristas a procurarem novos sistemas de produção e comercialização das mudas. Recipientes tradicionais, como sacolas plásticas com capacidade para um a três litros de substrato elevam o custo de produção, aumentam a necessidade de espaço no viveiro e elevam consideravelmente o custo do transporte das mudas (KITAMURA et al., 2004). Assim, a utilização de tubetes tem sido uma alternativa viável para a formação de mudas de espécies frutíferas.

A enxertia constitui-se em prática mundialmente consagrada na fruticultura, sendo usada em larga escala, nas principais espécies frutíferas, tanto de regiões de clima temperado como de clima tropical, e sua utilização permite a reprodução integral do genótipo que apresenta características desejáveis. Como vantagem adicional, a propagação por enxertia possibilita que as plantas entrem em fase de produção mais cedo (CARVALHO et al., 2000).

A produção de mudas através de sementes apresenta algumas desvantagens, como a grande variabilidade entre as plantas e sua produção, frutificação baixa e mais tardia, baixa qualidade dos frutos, elevado porte das plantas, entre outros (FRANZON et al., 2008).

A produção de mudas de fruteiras por enxertia, em geral, requer o crescimento do portaenxerto até atingir um diâmetro mínimo de caule de cerca de 7 a $10 \mathrm{~mm}$. Todavia, novos métodos têm sido perseguidos por pesquisadores para diminuir o tempo necessário para a produção das mudas. Experiências exitosas com graviola (KITAMURA et al., 2004), citros (OLIVEIRA et al., 2002), nogueiramacadâmia (CAMPO-DALL'ORTO et al., 1988) e maracujazeiro (RAMOS et al., 2008) demonstram a viabilidade da utilização de tubetes na produção de mudas comerciais.

Kitamura e Lemos (2004) observaram que a utilização de tubetes plásticos com capacidade para $230 \mathrm{~cm}^{3}$ de substrato, na produção de porta-enxertos, reduziu drasticamente a necessidade de substrato, o insumo mais caro do sistema de produção de mudas de gravioleira. Além disso, reduziu a necessidade de ocupação da área do viveiro e os custos de transporte sem reduzir a qualidade das mudas produzidas.

Altos índices de pegamento estão sempre associados a um estado fisiológico coincidente entre o porta-enxerto e o enxerto. Isso significa que ambas as partes devem estar vigorosas, em pleno crescimento e com boa circulação das seivas mineral e orgânica nos vasos de xilema e floema, respectivamente (OLIVEIRA et al., 2005).

Um bom porta-enxerto, de forma geral, deve ter, no ponto de enxertia, o diâmetro de um $\mathrm{cm}$ acerca de $20 \mathrm{~cm}$ acima do colo da planta (SIMÃO, 1998). Todavia, Kitamura e Lemos (2004), estudando a enxertia precoce em gravioleira, uma espécie de anonácea do mesmo gênero da pinheira, apresentaram a possibilidade de se produzirem enxertos com qualidade sobre porta-enxertos precocemente produzidos em tubetes com menos da metade do diâmetro e um terço da idade geralmente recomendada. O objetivo deste trabalho foi desenvolver um protocolo de produção de porta-enxertos em tubetes e determinar métodos para a enxertia precoce da pinheira para reduzir o volume do substrato, melhorar o aproveitamento do espaço no viveiro e reduzir o peso e o custo de transporte de mudas.

\section{MATERIAL E MÉTODOS}

O experimento foi conduzido de fevereiro a dezembro de 2007, no viveiro comercial de produção de mudas Chácara das Anonáceas, em Maceió - AL.

Os porta-enxertos foram produzidos de sementes retiradas de 100 frutos maduros coletados no município de Palmeira dos Índios - AL, lavadas em água corrente e colocadas para secar à sombra até o momento do plantio. As sementes selecionadas 
com tamanho superior a um $\mathrm{cm}$ de comprimento foram plantadas em tubetes plásticos de $150 \mathrm{~cm}^{3} \mathrm{e}$ $230 \mathrm{~cm}^{3}$, contendo substrato comercial para mudas Plantmax ${ }^{\circledR}$ (capacidade de retenção de água 150\%, pH 5.8, condutividade elétrica $12,2 \mathrm{mS} / \mathrm{cm}$ ).

Não foi utilizado nenhum método de quebra de dormência das sementes de pinheira. Após o plantio, os tubetes foram mantidos em telado com $50 \%$ de sombreamento e irrigações diárias de 20 minutos por microaspersão. As avaliações para a verificação da germinação foram realizadas durante quatro semanas.

Após a germinação das sementes, os portaenxertos selecionados foram medidos quinzenalmente, durante 30 semanas, em relação às variáveis de comprimento da planta, diâmetro do caule no ponto de enxertia ( $5 \mathrm{~cm}$ do colo), número de folhas e área foliar.

A área foliar foi estimada a partir da coleta de 100 folhas da zona mediana das mudas, nos dois tamanhos de tubete. As folhas coletadas tiveram suas áreas medidas após serem fotocopiadas e pesadas em balança de precisão para comparação de massa de área conhecida do mesmo papel. O número de folhas foi registrado a cada quinze dias, e a área foliar foi calculada com o auxílio da fórmula: $\mathrm{AF}=\mathrm{NFxM}$, em que AF (área foliar), NF (número de folhas) e M (média estimada para cada tamanho de tubete).

$\mathrm{O}$ experimento de enxertia foi organizado em blocos casualizados, com arranjo fatorial $(4 \times 3 \times 2)$, sendo quatro idades de porta-enxerto $(3 ; 5 ; 7$ e 9 meses), três tipos de enxertia (borbulhia em escudo, garfagem de topo em fenda cheia e garfagem lateral em fenda cheia) e dois tamanhos de tubetes $\left(150 \mathrm{~cm}^{3}\right.$ e $230 \mathrm{~cm}^{3}$ ), perfazendo o total de 24 tratamentos e 15 repetições.

Os enxertos foram colhidos de plantas sadias e vigorosas, com cinco anos de idade, cultivadas no município de Palmeira dos Índios - AL, e tiveram as suas folhas cortadas em sua totalidade antes de serem umedecidos, acondicionados em papel-toalha e postos dentro de sacos plásticos, por 24 horas, até o momento da enxertia.

O procedimento da enxertia foi feito com estilete limpo, fita biodegradável e pequenos sacos transparentes para a cobertura dos enxertos, evitando, assim, seu dessecamento (KITAMURA et al., 2004). As enxertias por borbulhia e garfagem foram feitas de acordo com a metodologia proposta por Kitamura e Lemos (2004). A borbulhia em escudo consistiu na realização de um único corte descendente no portaenxerto, a uma altura de $5 \mathrm{~cm}$ do colo, e fixação da borbulha feita com a fita biodegradável. Na garfagem de topo, procedeu-se à decapitação do porta-enxerto, a uma altura de $4 \mathrm{~cm}$, a partir do colo da planta. Em seguida, fez-se um corte vertical em fenda cheia com $1 \mathrm{~cm}$ de comprimento. No garfo, fez-se um corte em bisel, com $1 \mathrm{~cm}$ de comprimento na extremidade inferior. A garfagem lateral seguiu esse mesmo procedimento, mudando o corte do topo para a lateral do porta-enxerto. Após a inserção do garfo sobre a fenda produzida no porta-enxerto, utilizou-se uma fita biodegradável para unir os tecidos. Finalmente, cobriu-se o enxerto com um pequeno saco plástico transparente preso logo abaixo do enxerto.

Foram utilizados 90 porta-enxertos para cada idade, divididos nos dois tamanhos de tubetes. Após a enxertia, as plantas foram colocadas sob telado, com $80 \%$ de sombreamento, até a caracterização do pegamento, aos 21 dias. Posteriormente, as mudas foram levadas para a aclimatização sob telado com $50 \%$ de sombreamento, por mais 15 dias, e, após esse período, foram levadas para o sol pleno e computadas as porcentagens de pegamento dos enxertos. Os dados coletados foram submetidos à análise de variância, e as médias, comparadas com o auxílio do teste de Tukey, a 5\% de probabilidade, de acordo com a metodologia proposta por Ferreira (1996).

\section{RESULTADOS E DISCUSSÃO}

Embora não se tenha utilizado nenhum método para a quebra da dormência das sementes, observou-se germinação entre 70 e $82 \%$ após quatro semanas da semeadura, o que não representou diferenças significativas entre os diferentes tamanhos de tubete (Figura 1). Stenzel et al. (2003), estudando a superação da dormência em sementes de atemoia e fruta-do-conde, utilizando concentrações de 50 ppm e 100 ppm de $\mathrm{GA}_{3}$, obtiveram resultado de germinação de 75 e $43,75 \%$, respectivamente, entre o $7^{\circ}$ e o $38^{\circ}$ dia.

As mudas dos tubetes de $230 \mathrm{~cm}^{3}$ apresentaram comprimento significativamente superior quando comparado às mudas dos tubetes de $150 \mathrm{~cm}^{3}$ (Figura 2). O maior volume de substrato disponível nos tubetes de $230 \mathrm{~cm}^{3}$ proporcionou maior capacidade de absorção de nutrientes pelas raízes e, consequentemente, maior desenvolvimento da planta. $\mathrm{O}$ crescimento das mudas de fruteiras em viveiro tem sido sempre associado ao vigor da semente, sanidade das plantas, disponibilidade de nutrientes e volume do substrato (SCHIAVO; MARTINS, 2002). Trabalhos realizados para verificar o efeito do volume do recipiente no crescimento e desenvolvimento de plantas, têm mostrado que a restrição radicular pode diminuir o crescimento das raízes e da parte aérea das 
plantas (PETERSON et al.,1991b). Sugere-se que o processo envolvido nessa redução do crescimento inclua a inibição da elongação foliar (PETERSON et al., 1991a), fotossíntese (ISMAIL; NOOR, 1996), mudança na partição da matéria seca da planta e absorção de nutrientes (BAR-TAL; PRESSMAN, 1996) e metabolismo hormonal (PETERSON et al., 1991a, 1991b).

O número de folhas presentes nas mudas de pinheira aumentou até a $16^{\mathrm{a}}$ semana de cultivo e esteve, até aquele momento, associado ao comprimento do caule. Entretanto, o ataque de fungos da espécie Colletotrichum gloeosporioides, coincidindo com um período de chuvas, favoreceu a queda de folhas mais velhas e reduziu o número total de folhas das mudas. A aplicação de fungicida à base de oxicloreto de cobre não foi suficiente para conter a infecção. Entretanto, o número de folhas foi significativamente superior nos tubetes de $230 \mathrm{~cm}^{3}$. Mesmo após a queda das folhas infectadas, o número de folhas permaneceu proporcional ao número produzido antes do ataque (Figura 3).

Oliveira et al. (2008) observaram que o cultivo em tubetes de $115 \mathrm{~cm}^{3}$ proporcionou resultados inferiores em crescimento das plantas àqueles observados em tubetes de $180 \mathrm{~cm}^{3}$, mas esse fator não influenciou na sobrevivência das plantas, sugerindo que seu emprego poderia ser útil em curtos períodos de aclimatização. Eles sugeriram que o uso de tubetes constitui-se numa alternativa para economia de material, pois menor quantidade de substrato é necessária para o preenchimento dos tubetes, além de requererem menor espaço físico, tempo na execução do trabalho e, consequentemente, menor custo na produção.

Estudando o comportamento de mudas de abacaxizeiro micropropagadas sob a influência de diferentes substratos e recipientes, Souza Júnior et al. (2001) não observaram superioridade do uso de tubetes grandes em relação a tubetes pequenos. De acordo com seus resultados, o cultivo em tubetes pequenos suplantou os tubetes grandes quanto às variáveis de crescimento da parte aérea e do sistema radicular, exceção observada apenas para o diâmetro do colo. No entanto, de acordo com Reis et al. (1989), a restrição do crescimento de raízes provocada pelo volume do recipiente pode promover o desequilíbrio da razão raízes: parte aérea, alterando as respostas fisiológicas das plantas cultivadas.

No trabalho aqui apresentado, estimou-se a área média de $100 \mathrm{~cm}^{2}$ e $225 \mathrm{~cm}^{2}$ para cada folha das plantas nos tubetes pequenos e grandes, respectivamente. A área foliar medida do início até a décima semana do experimento aumentou em mais de dez vezes nas mudas dos tubetes de $230 \mathrm{~cm}^{3}$ e em cerca de 4 vezes nos tubetes de $150 \mathrm{~cm}^{3}$. Após a $16^{\mathrm{a}}$ semana, seguiu-se uma redução na área foliar das mudas, acompanhando a queda das folhas provocada pelo ataque da antracnose. Contudo, observou-se que as mudas dos maiores tubetes tiveram índice significativamente maior de área foliar (cerca de 2,5 vezes) em relação às mudas de tubetes menores (Figura 4).

Um fator a ser considerado na produção de mudas de fruteiras são os recipientes nos quais as plantas são cultivadas, pois o volume do recipiente poderá exercer influência decisiva no desenvolvimento e manutenção do ativo crescimento das plantas durante as etapas de aclimatização e enviveiramento (OLIVEIRA et al., 2008). Segundo Reis et al. (1989), o desempenho no campo é maior à medida que as dimensões das mudas, por ocasião do plantio, forem maiores. A restrição do sistema radicular limita o crescimento e o desenvolvimento de várias espécies, pela redução da área foliar, altura e produção de biomassa. Ainda segundo esses autores, o pequeno volume dos recipientes exige, também, a aplicação de doses elevadas de nutrientes, devido às perdas por lixiviação, resultantes da necessidade de regas frequentes.

O diâmetro do caule, no ponto da enxertia, também variou significativamente entre as mudas cultivadas nos dois tamanhos de tubetes. $\mathrm{O}$ incremento no diâmetro do caule variou de um mm (após dez semanas) a dois mm (após 30 semanas) em favor das mudas dos tubetes maiores, mostrando o efeito da maior produção de fotossintatos nos tratamentos com maior área foliar para a construção dos tecidos do caule (Figura 5).

De acordo com a análise de variância, houve diferença significativa entre as idades dos porta-enxertos e os diferentes tipos de enxertia e a interação entre eles; contudo, não foi observada diferença significativa em relação ao tamanho do tubete (Tabela 1). Em relação aos tipos de enxertia utilizados, os métodos de garfagem foram superiores quando comparados com o método de borbulhia, independentemente da idade do porta-enxerto e do tamanho do tubete utilizado (Figura 6). Aos três meses de idade dos porta-enxertos, as taxas de pegamento dos enxertos já havia atingido mais de $95 \%$ para o método de garfagem de topo em fenda cheia e de $60 \%$ para o método de garfagem lateral em fenda cheia; o pegamento dos enxertos feitos por borbulhia, aos 3 meses, foi inferior, em média, a 27\%. Desse modo, observou-se um crescimento do pegamento dos enxertos significativo para este método com relação à idade do porta-enxerto, chegando a $90 \%$ aos 7 meses, igualando-se, assim, aos métodos de garfagem em fenda cheia e lateral, com 90 e $83,33 \%$ de pegamento, respectivamente (Tabela 2). $\mathrm{O}$ aumento 
no diâmetro dos porta-enxertos e a lignificação do lenho, possibilitando a melhor separação da casca, pode ter favorecido esse crescimento.

As enxertias realizadas aos sete e nove meses de idade dos porta-enxertos não apresentaram mais diferenças significativas entre os tratamentos, e as taxas de pegamento foram sempre superiores a $70 \%$, independentemente do tipo de enxertia e do tamanho do tubete (Figura 7).
Para Campo-Dall'Orto (1988), o portaenxerto novo, fino e tenro, e, consequentemente, o garfo também fino e pouco lignificado possibilitaram ao enxertador facilidades na escolha do material e no corte, resultando maior rendimento na operação de enxertia de nogueira-macadâmia. Isso propiciou corte mais uniforme do material e melhor união do enxerto/porta-enxerto, o que teria influído, decisivamente, no melhor pegamento.

TABELA 1 - Análise de variância para porcentagem de pegamento de enxertia precoce em pinheira $(A n-$ nona squamosa L.). Maceió - AL, 2007.

\begin{tabular}{lcccc}
\hline F.V. & G.L & S.Q. & Q.M. & F \\
\hline IPE $^{1}$ & 3 & 8283.33333 & 2761.1111 & $7.2029 * *$ \\
TT & 1 & 672.222222 & 672.22222 & $1.7536 \mathrm{~ns}$ \\
TE & 2 & 8811.11111 & 4405.5556 & $11.4928 * *$ \\
IPExTT & 3 & 1083.33333 & 361.11111 & $0.9420 \mathrm{~ns}$ \\
IPExTE & 6 & 9766.66667 & 1627.7778 & $4.2464 * *$ \\
TTxTE & 2 & 1944.44444 & 972.22222 & $2.5362 \mathrm{~ns}$ \\
IPExTTxTE & 6 & 4633.33333 & 772.22222 & $2.0145 \mathrm{~ns}$ \\
\hline Tratamentos & 23 & 35194.44444 & 1530.19324 & $3.9918 * *$ \\
Resíduo & 48 & 18400.00000 & 383.33333 & \\
Total & 71 & 53594.44444 & \\
\cline { 1 - 3 }
\end{tabular}

1. IPE - Idade do porta-enxerto; TT - Tamanho do tubete; TE - Tipo de enxertia

**- Significativo ao nível de $1 \%$ de probabilidade

ns - Não significativo pelo teste $\mathrm{F}$

TABELA 2 - Porcentagem do pegamento dos enxertos em função da idade do porta-enxerto e do tipo de enxertia em pinheira (Annona squamosa L.). Maceió - AL, 2007.

\begin{tabular}{|c|c|c|c|}
\hline \multirow[b]{2}{*}{ Idade do porta-enxerto } & \multicolumn{2}{|c|}{ Tipo de enxertia } & \multirow[b]{2}{*}{ Fenda lateral } \\
\hline & Borbulhia & Fenda cheia & \\
\hline 3 meses & $26,67 \mathrm{cC}$ & 96,67 aA & $60,0 \quad b B$ \\
\hline 5 meses & $50,0 \quad \mathrm{bcB}$ & 73,33 aA & 80,0 \\
\hline 7 meses & $90,0 \quad \mathrm{aA}$ & $90,0 \quad \mathrm{aA}$ & 83,33 aA \\
\hline 9 meses & 73,33 abA & 86,67 aA & 86,67 aA \\
\hline $\begin{array}{c}\text { Médias dos } \\
\text { tipos de enxertia }\end{array}$ & $60 \mathrm{~b}$ & $86 \mathrm{a}$ & $77,5 \mathrm{a}$ \\
\hline $\mathrm{CV} \%$ & 24,31 & 19.98 & 19,97 \\
\hline
\end{tabular}

Médias na coluna seguidas de mesma letra minúscula e na linha por letra maiúscula não diferem entre si, pelo teste de Tukey, a 5\% de probabilidade. 


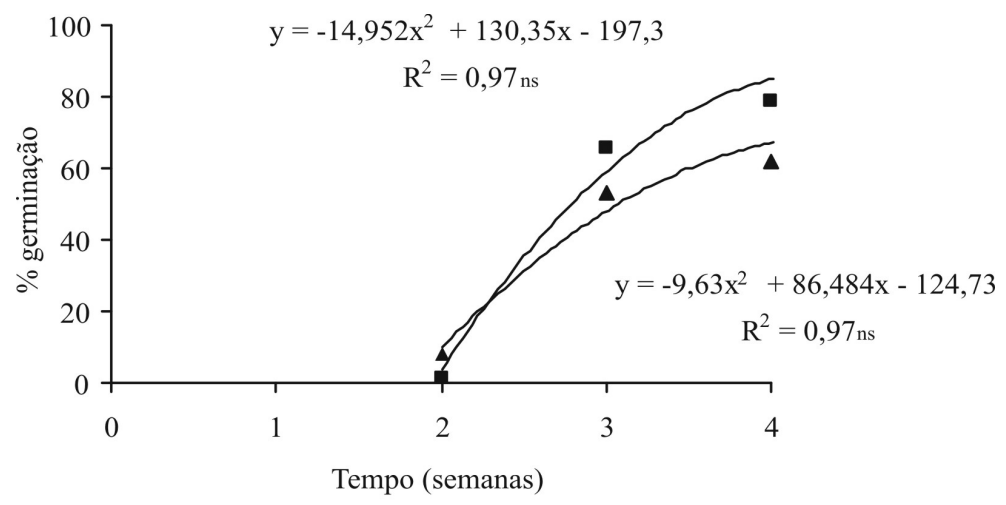

$\Delta$ Tubetes $150 \mathrm{~cm}^{3}$ 口 Tubetes $230 \mathrm{~cm}^{3}$

FIGURA 1 - Volume do tubete em relação à germinação de sementes de pinha durante quatro semanas de avaliação em viveiro. Maceió - AL, 2007.

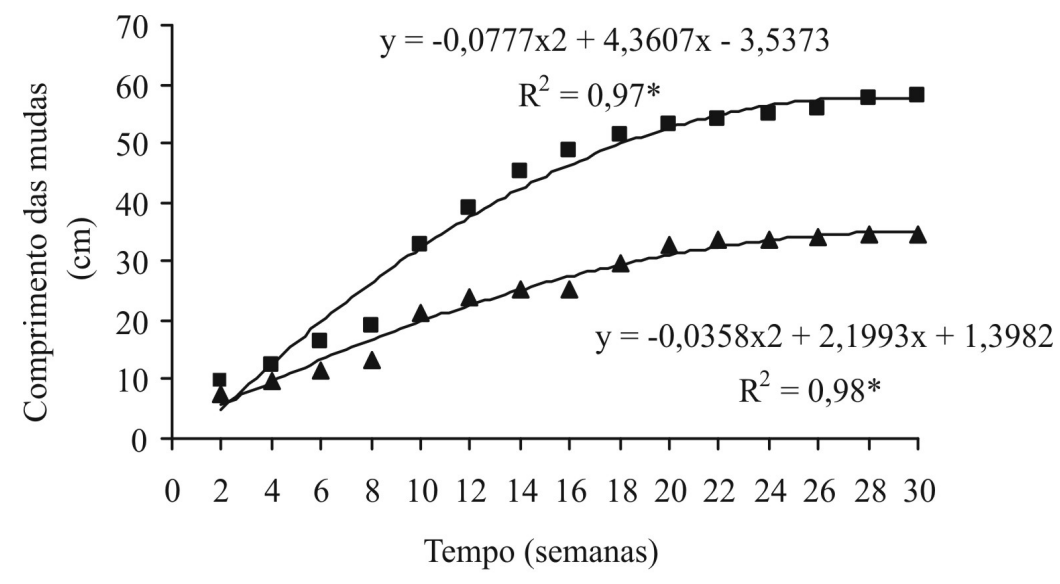

$\square$ Tubetes $230 \mathrm{~cm}^{3} \Delta$ Tubetes $150 \mathrm{~cm}^{3}$

FIGURA 2 - Volume do tubete em relação ao comprimento dos caules dos porta-enxertos de pinha durante 30 semanas de avaliação em viveiro. Maceió - AL, 2007.

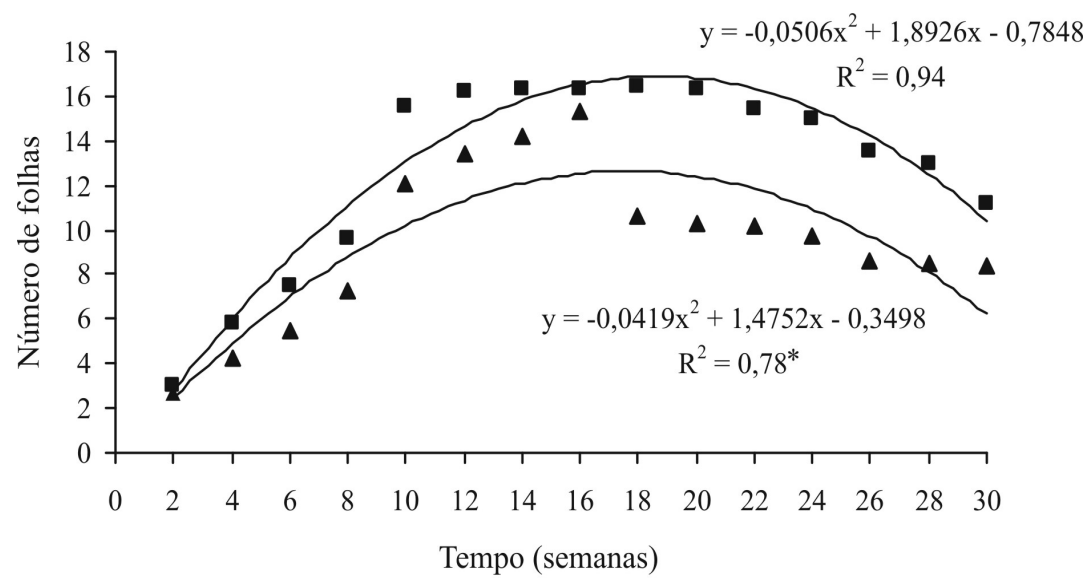

$\Delta$ Tubetes $150 \mathrm{~cm}^{3}$ 口 Tubetes $230 \mathrm{~cm}^{3}$

FIGURA 3 - Volume do tubete em relação ao número de folhas em porta-enxertos de pinha durante 30 semanas de avaliação do crescimento em viveiro. Maceió - AL, 2007. 


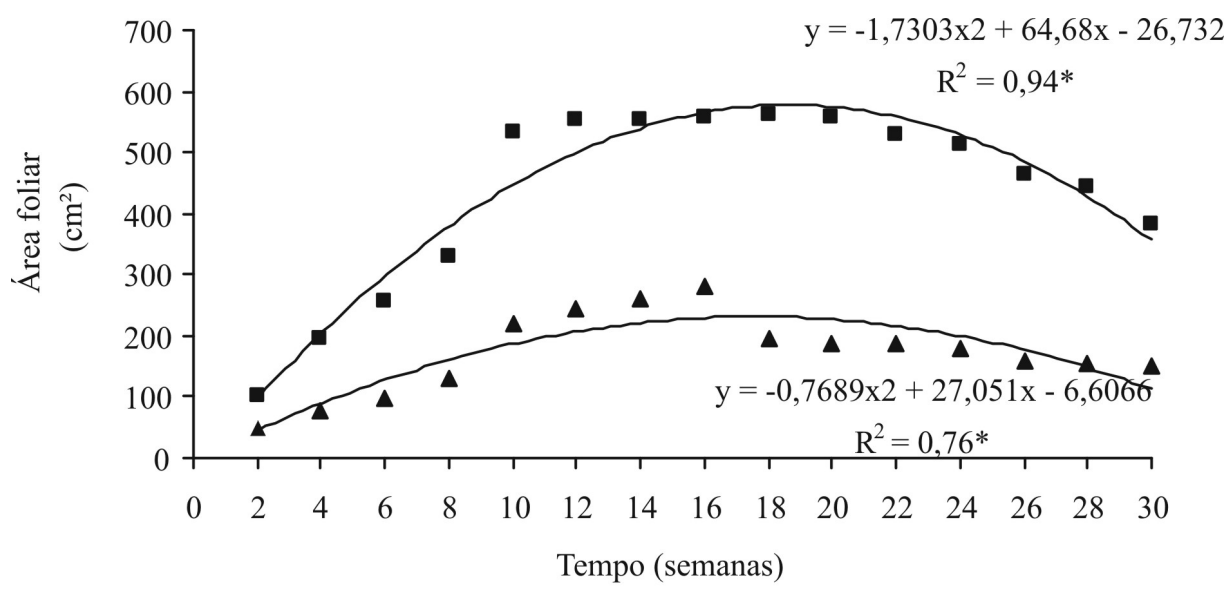

FIGURA 4 - Volume do tubete em relação à área foliar dos porta-enxertos de pinha durante 30 semanas de avaliação em viveiro. Maceió - AL, 2007.

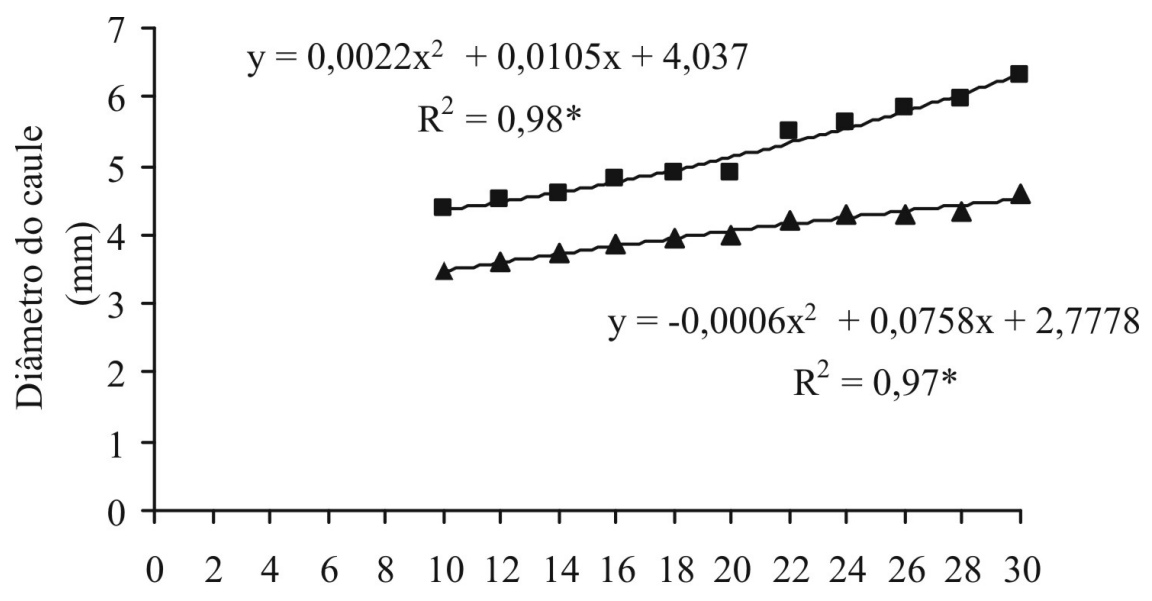

FIGURA 5 - Volume do tubete em relação ao diâmetro dos caules dos porta-enxertos de pinha durante 30 semanas de avaliação em viveiro. Maceió - AL, 2007.

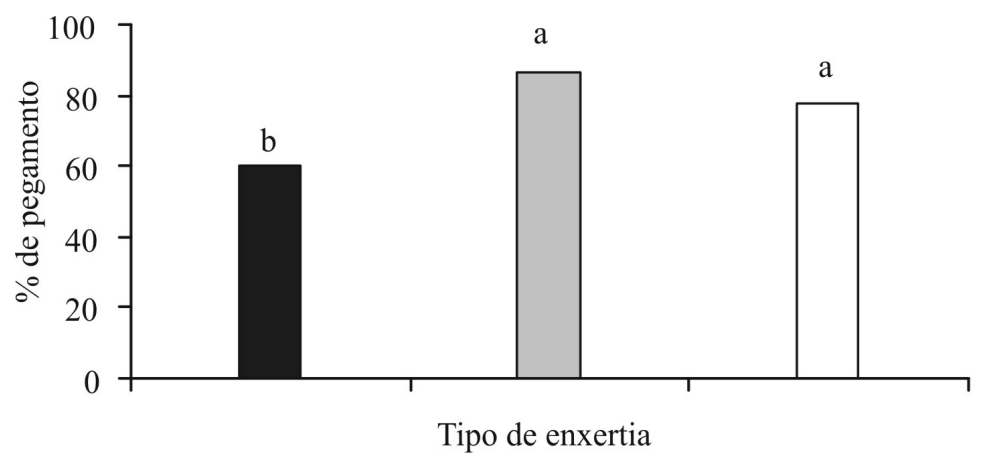

Borbulhia em escudo $\square$ Garfagem de topo em fenda cheia

$\square$ Garfagem lateral em fenda cheia

FIGURA 6 - Pegamento dos enxertos de pinheira (Annona squamosa L.) em relação ao tipo de enxertia. Letras iguais não diferem entre si, pelo teste de Tukey ( $\mathrm{P}>0.05)$. Maceió - AL, 2007. 


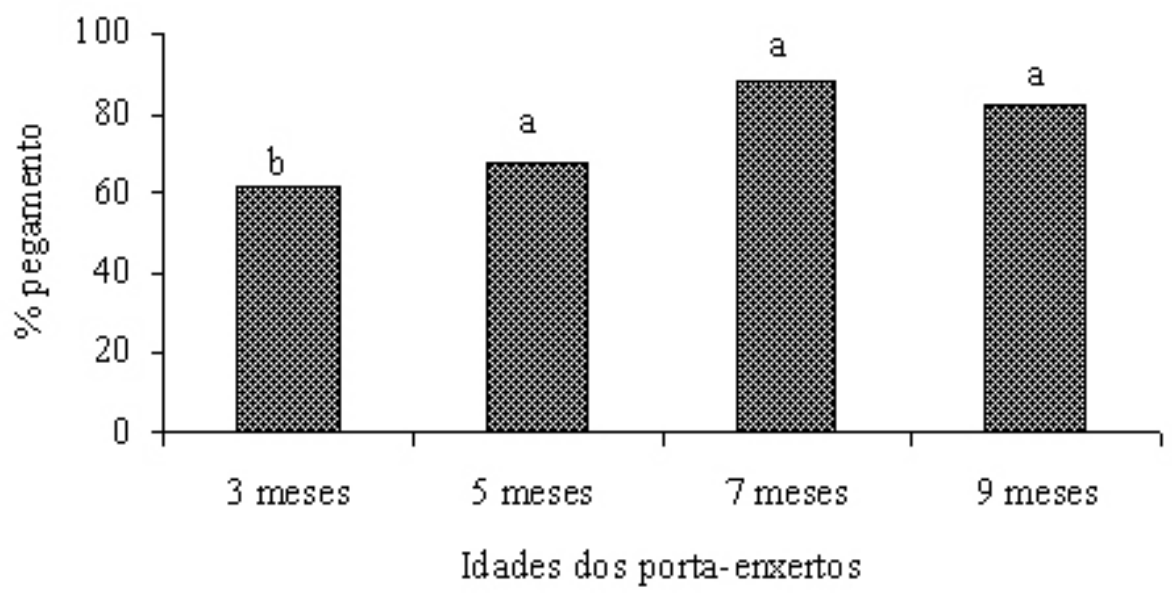

FIGURA 7 - Pegamento dos enxertos de pinheira (Annona squamosa L.) em relação à idade dos portaenxertos, independentemente do tipo de enxertia utilizado.

Letras iguais não diferem entre si, pelo teste de Tukey $(\mathrm{P}>0.05)$. Maceió - AL, 2007.

\section{CONCLUSÕES}

1-Os porta-enxertos produzidos em tubetes de $230 \mathrm{~cm}^{3}$ apresentaram comprimento, número de folhas, área foliar e diâmetro do caule relativamente superiores quando comparados com os desenvolvidos em tubetes de $150 \mathrm{~cm}^{3}$.

2-O tamanho do tubete não influencia no pegamento dos enxertos de pinha feitos pelos métodos de enxertias utilizados, sendo considerados apropriados para a produção de mudas precoces de pinheira.

3-A idade do porta-enxerto influencia significativamente no pegamento dos enxertos por garfagem lateral e por borbulhia, que atingem níveis ótimos a partir do $5^{\circ}$ e $7^{\circ}$ meses, respectivamente.

4-A enxertia precoce reduz o tempo necessário para a produção de mudas clonais de pinheira em cerca de seis a oito meses, quando comparado com o sistema convencional de enxertia em mudas, em sacolas plásticas.

\section{AGRADECIMENTOS}

Ao CNPq e à FAPEAL, pelo apoio financeiro ao projeto.

\section{REFERÊNCIAS}

BAR-TAL, A.; PRESSMAN, E. Root restriction and potassium and calcium solution concentrations affect dry-matter production, cation up-take, and blossom-end rot in geenhouse tomato. Journal of the American Society for Horticultural Science, Alexandria, v. 121, p. 649-655, 1996.

CAMPO-DALL'ORTO, F. A.; OJIMA, M.; BARBOSA, W.; SABINO, J. C.; RIGITANO, O. Enxertia precoce da nogueira-macadâmia, Bragantia, Campinas, v.47 n.2, p.195-211,1988.

CARVALHO, J.E.U.de; RIBEIRO, M.A.C.; NASCIMENTO, W. M. O. do; MULLER, C.N. Enxertia da gravioleira (Annona muricata L.) em porta-enxertos dos gêneros Annona e Rollinia. Belém: Embrapa Amazônia Oriental, 2000. 4p. (Comunicado Técnico, 27).

FRANZON, R. C.; GONÇALVES, R. S.; ANTUNES, L. E. C.; RASEIRA, M. C. B. Propagação da pitangueira através da enxertia de garfagem. Revista Brasileira de Fruticultura, Jaboticabal, v. 30, n. 2, p. 488-491, 2008.

FERREIRA, P. V. Estatística experimental aplicada à agronomia. 2.ed. Maceió: EDUFAL, 1996. 
ISMAIL, M.R.; NOOR, K.M. Growth, water relations and physiological processes of starfruit (Averrhoa carambola L.) plants under root growth restriction. Scientia Horticultural, Amsterdam, 66, p.51-58, 1996.

KITAMURA, M.C.; LEMOS, E.E.P. Enxertia precoce da gravioleira (Annona muricata L.). Revista Brasileira de Fruticultura, Jaboticabal, v.26, p.186188, 2004.

KITAMURA, M.C.; RAMOS, J.D.; LEMOS, E.E.P. Avaliação de tipos de enxertia e recipientes para produção de mudas de grvioleira (Annona muricata L.). Ciência e Agrotecnologia, Lavras, v.28, p.2433, 2004.

LEON, J. Botânica de los cultivos tropicales. San José: IICA, 1987.

OCHSE, J.J.; SOULE JR., M.J.; DIJKMAN, M.J.; WEHLBURG, C. Otros cultivos frutales. In: Cultivo y mejoramiento de plantas tropicales e subtropicales. México: Ed. Limusa, 1974. p.587818.

OLIVEIRA, J. P.; COSTA, F. H. S.; PEREIRA, J. E. S. Crescimento de mudas micropropagadas de bananeira aclimatizadas nas condições da Amazônia Sul Ocidental sob a influência de diferentes substratos e recipientes. Revista Brasileira de Fruticultura, Jaboticabal, v.30, n.2 p.84-87, 2008.

OLIVEIRA, I.V.M.; DAMIÃO FILHO, C.F.; CARVALHO, S.A. Enxertia em citros por substituição de ápice caulinar. Revista Brasileira de Fruticultura, Jaboticabal, v.24, n.3, p.744-747, 2002.

OLIVEIRA, Z.P.O.; QUEIROZ, F.M.; BARROS, P.G.; CAMPOS, R.S.; LEMOS, E.E.P.; NETO, J.P.S. Recomendações técnicas para a cultura da pinheira. Maceió: SEAGRI, 2005. 56p. (Boletim, 1).

PETERSON, T.A.; COHEN, J.D.; BUTA, J.G.; KRIZEK, D.T. Influence of root restriction on tomato: Changes in leaf cell expansion, abscisic acid and indole-3-acetic acid. Plant Physiology, Minneapolis, v. 96, p.78, 1991a. Suppl.
PETERSON, T.A.; REINSEL, M.D.; KRIZEK, D.T. Tomato (Lycopersicum esculentum Mill., cv. 'Better Bush') plant response to root restriction. Journal of Experimental Botany, Oxford, v.42, n.243, p.12331240, 1991b.

PINTO, A.C.Q.; CORDEIRO, M.C.R.;ANDRADE, S.R.M.; FERREIRA, F.R.; FILGUEIRAS, H.A.C.; ALVES, R.E.; KIMPARA, D.J. Fruits for the future 5: Annona species. Southhampton: IPGRI, 2005. 263p.

RAMOS, J.D.; SANTOS, V.A.; CHALFUN, N.N.J.; FERREIRA, E.A.; HAFLE, O.M.; COSTA, A.C. Enxertia precoce na produção de mudas do maracujazeiro. In: CONGRESSO BRASILEIRO DE FRUTICULTURA, 20., ANNUAL MEETING OF THE INTERAMERICAN SOCIETY FOR TROPICAL HORTICULTURE, 54., 2008, Vitória. Resumos...

REIS, G.G.; REIS, M.G.F.; MAESTRI, M.; XAVIER, A.; OLIVEIRA, L.M. Crescimento de $E u$ calyptus camaldulensis, E. grandis e E. cloeziana sob diferentes níveis de restrição radicular. Revista Árvore, Viçosa, MG, v.13, n.1, p.1-18, 1989.

SCHIAVO, J. A.; MARTINS, M. A. Produção de mudas de goiabeira (Psidium guajava L.), inoculadas com o fungo micorrízico arbuscular Glomus clarum, em substrato agro-industrial. Revista Brasileira de Fruticultura, Jaboticabal, v.24, n.2, p. 519-523, 2002.

SIMÃO, S. Tratado de fruticultura. Piracicaba: FEALQ, 1998. 760p.

SOUZA JÚNIOR, E.E. de; BARBOZA, S.B.S.C.; SOUZA, L.A.C. Efeitos de substratos e recipientes na aclimatação de plântulas de abacaxizeiro [Ananás comosus (L.) Merril] cv. Pérola. Pesquisa Agropecuária Tropical, Goiânia, v.1, n.2, p.147-151, 2001.

STENZEL, N. M. C.; MURATA, I. M.; NEVES, C. S. V. J. Superação da dormência em sementes de atemoia e fruta-do-conde. Revista Brasileira de Fruticultura, Jaboticabal, v.25, n. 2, p. 305308, 2003. 